\section{REDIMAT}

Journal of Research in Mathematics Education
Hipatia Press

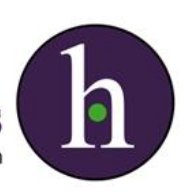

Instructions for authors, subscriptions and further details:

http://redimat.hipatiapress.com

\title{
The Symbolic World of Mathematics
}

Thomas Lingefjärd ${ }^{1}$ and Djamshid Farahani ${ }^{1}$

1) University of Gothenburg

Date of publication: June $24^{\text {th }}, 2017$

Edition period: June 2017-October 2017

To cite this article: Lingefjärd, T. (2017). The symbolic world of

Mathematics. REDIMAT, 6(2), 118-135. doi: 10.1783/redimat.2017.2391

To link this article: http://dx.doi.org/10.17583/redimat.2017.2391

\section{PLEASE SCROLL DOWN FOR ARTICLE}

The terms and conditions of use are related to the Open Journal System and to Creative Commons Attribution License (CC-BY). 


\section{The Symbolic World of Mathematics}

\author{
Thomas Lingefjärd \\ University of Gothenburg
}

Djamshid Farahani

University of Gothenburg

(Received: 15 November 2016; Accepted: 27 May 2017; Published: 24 June 2017)

\section{Abstract}

In understanding upper secondary school students' interpretations of information in symbolic representations of a distance-time-relation, little attention has been paid to the analysis of the condition of the conceptual development related to utterances. Understanding this better can help improve the teaching of attribute and information in symbolic representations of different phenomena. Two theoretical perspectives have been used to conduct the analysis: Tall and Vinner's theoretical perspectives on learning and Gray's \& Tall's theory of three mathematical worlds together with Hähkiöniemi's interpretation of these three worlds. The findings provide evidence that a detailed analyse of student's utterances show difference in quality related to student's interpretations of a distance-time relation. The qualities were related to student's concept images of functions and derivatives.

Keywords: Conceptual development, symbolical representations, interpretations 
REDIMAT, Vol. 6 No. 2 Junio 2017 pp. 138-135

\title{
El Mundo Simbólico de las Matemáticas
}

\author{
Thomas Lingefjärd \\ University of Gothenburg
}

(Received: 15 Noviembre 2016; Accepted: 27 Mayo 2017; Published: 24 Junio 2017)

\section{Resumen}

En la comprensión de las interpretaciones de los estudiantes de la escuela secundaria en representaciones simbólicas de una relación distancia-tiempo, se ha prestado poca atención al análisis de la condición del desarrollo conceptual relacionado con los enunciados. Entender esto mejor puede ayudar a mejorar la enseñanza del atributo y de la información en representaciones simbólicas de diferentes fenómenos. Se han utilizado dos perspectivas teóricas para llevar a cabo el análisis: las perspectivas teóricas de Tall y Vinner sobre el aprendizaje y la teoría de Gray y Tall de tres mundos matemáticos junto con la interpretación de Hähkiöniemi de estos tres mundos. Los hallazgos proporcionan evidencia de que un análisis detallado de los enunciados de los estudiantes muestra diferencias en calidad relacionadas con las interpretaciones de los estudiantes de la relación distancia-tiempo. Las cualidades estaban relacionadas con las imágenes conceptuales de funciones y de sus derivadas.

Palabras clave: Desarrollo conceptual, representaciones simbólicas, interpretaciones. 


\section{Lingefjärd \& Farahani - The Symbolic World of Mathematics}

$\mathrm{M}$ athematical representations such as diagrams, histograms, functions, graphs, tables and symbols facilitate understanding and communication of abstract mathematical concepts or other phenomenon described in mathematical terms (Elby, 2000; Leinhardt, Zaslavsky, \& Stein 1990). Nevertheless, humans of today are facing a world that is shaped by increasingly complex, dynamic, and powerful systems of information that we meet through various media.

An important aspect of the problem we gave the students is that it is a symbolical representation of a theoretical physical concept's motion. Being able to interpret, understand, and work with symbolical representations involves mathematical processes and concepts the student needs to appreciate and comprehend and can address when facing interpretation challenges (Friel, Curcio \& Bright, 2001).

For mathematics education in an elementary, middle, lower secondary and upper secondary perspective, teachers use different representations to make it possible for students to gradually understand more and more complex mathematical objects and concepts. Geometrical constructions, graphs of functions, and a variety of diagrams of different kinds are used to introduce new concepts and to study relations, dependency and change (Trigueros \& Martínez-Planell, 2010). Mathematical representations, structures and constructions are also used in different scientific branches, such as biology, chemistry, physics or social science. It is of major importance that students learn how to interpret symbolical representations in a scientific and successful way.

Understanding a symbolic representation of a phenomenon involves the ability of relating different concepts incorporated in the specific representation. The critical problem of transition between and within representations has been addressed in several studies (Breidenbach, Hawks, Nichols, \& Dubinsky, 1992; Sfard, 1992). Lingefjärd \& Farahani (2016) claims that the ability of bridging the gap between symbolic and graphic representations depends highly on how students encapsulated relevant concepts involving in the representation.

\section{Research Questions}

(a) How do students interpret and understand symbolical representations of linear motion? 
(b) How do students use their interpretation in order to investigate special features of the linear motion?

\section{Theoretical Framework}

Many concepts we meet in mathematics have been encountered in some form or other before they are formally defined. Tall (2004) claims that mathematical thinking is strongly related to the cognitive process that give rise to mathematical knowledge. Learning or conceptual development in mathematics is seen as a change in the individual's concept image.

We shall use the term concept image to describe the total cognitive structure that is associated with the concept, which includes all the mental pictures and associated properties and processes. (Tall \& Vinner, 1981, p.152)

The usual notion of a definition of the concept in mathematics, according to Tall et al., (1981) is called concept definition.

The concept definition [is] a form of words used to specify that concept.

(Tall et al., 1981, p.152)

As the concept image develops it need not be coherent always. Different stimuli can most likely activate different parts of the concept image.

We shall call the portion of the concept image which is activated at a particular time the evoked concept image. At different times, seemingly conflicting images may be evoked. (Tall et al., 1981, p.152)

Tall (2004) suggests a possible categorisation of cognitive growth into three worlds of mathematics or three distinct but interacting developments. Three worlds of mathematics are founded on the assumption that the learning of mathematical concepts is individual and develop at different stages, through perception, through symbols or through axioms.

The first world is the conceptual-embodied world, the world we meet through perception, the visual and spatial mathematical world. Most of us have a concept image of what a circle is. A circle is round, it may be large or small and it may be red or blue. We have not learned this through educational efforts; instead we have learned this through the physical world and through observations. The first mathematical world consists of objects we have discovered and observed in the real world, knowledge we have 


\section{Lingefjärd \& Farahani - The Symbolic World of Mathematics}

gained through our senses. It also contains mental conceptions of nonexisting objects such as point with no size and lines with no thickness.

The second world is the proceptual - symbolic world. In this world, we find symbols and actions that we must perform when we, for example, are dealing with manipulations in algebra. Central in this world is the concept of procept which consist of the first part of process and the end of the word concept. Gray \& Tall (1994) introduced the concept procept to describe a central part of the learning of mathematical concepts. Gray et al. (1994) underlined that it is important to learn how to apprehend mathematical symbols both as concepts and as parts of a process at the same time.

An elementary procept is the amalgam of three components: a process which produces a mathematical object, and a symbol which is used to represent either process or object. (Gray et al., 1994, p. 12)

According to Gray et al. (1994) $2 \times 3$ may be perceived as a process (multiplication) or as a concept (product). Regarding learning in the symbolic world of mathematics he/she may use and reflect over the mathematical symbolic language and its function, meaning and application.

The third mathematical world is the formal axiomatic world. Is this world there are axioms, theorems and proofs in focus. Based on given assumptions regarding the proportion and relation between mathematical objects are axiom based structures built and used as foundations for mathematical theorems.

Mathematical thinking is thereby based on perception developing subtly in sophistication through the mental world of conceptual embodiment. The development takes account of the individual's previous experience which may operate successfully in one context yet remain supportive or become problematic in another, giving rise to emotional reactions to mathematics, leading to a spectrum of success and failure over the longer term (Tall, 2004).

The theories from Tall et al. (1981) and Gray et al. (1994) about cognitive development of mathematical knowledge is in many ways quite comparable with the historical development of mathematics as an axiomatic science.

Hähkiöniemi (2006) has used the theory of three mathematical worlds when investigating student's conceptions of derivative. Hähkiöniemi offers a hypothetical schema over learning of derivative building on a 
classification of representations that are frequent when introducing the concept of derivative (see Figure 1).

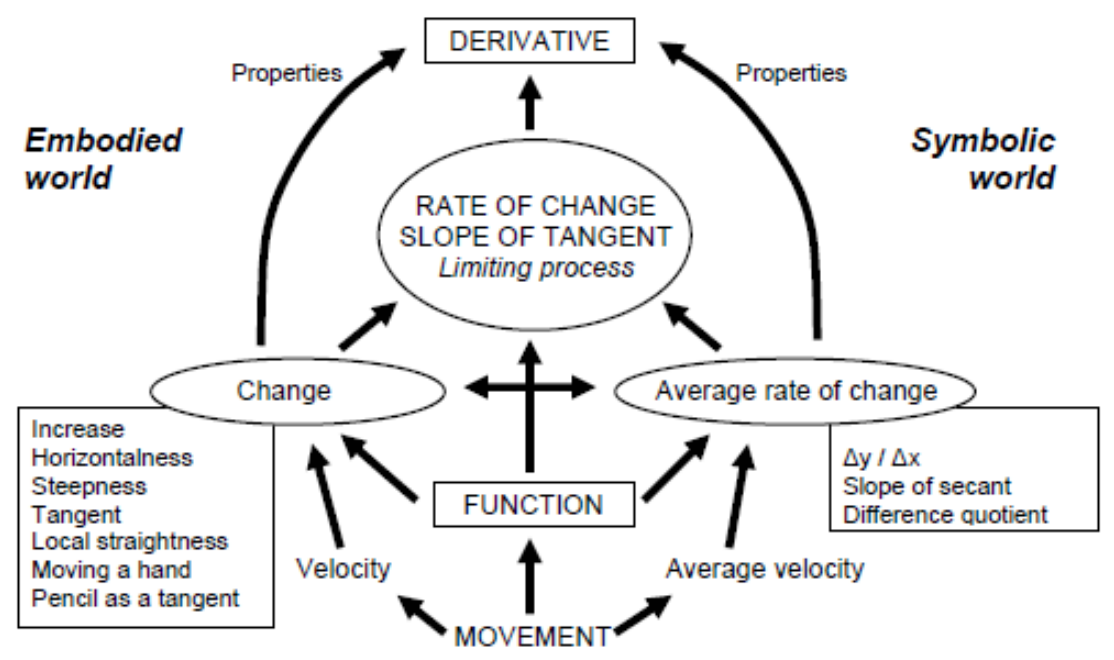

Figure 1. The learning path to the derivative (Hähkoneimi, 2006, p. 74).

It is obvious that humans may take different paths towards understanding or using the derivative in our construction of mathematical knowledge. We interpret this classification as once we have chosen our path, it also limits our choices.

\section{Methodology}

This study relies on qualitative approaches regarding methodology and analysis. The qualitative research method creates the opportunity to make a detailed analysis of how few students perceives a certain phenomenon or a certain concept. Our aim was to find a credible explanation that describes student's interpretations and explanations of symbolic description of a phenomenon together with conceptual development related to their utterances. 


\section{Lingefjärd \& Farahani - The Symbolic World of Mathematics}

Our first study took place in the fall of 2013 with 17 upper secondary school students at the natural science programme (nine girls and eight boys) in year 2. The students were all 18 years old or older and had studied at least three different mathematics courses at upper secondary school, calculus inclusive. All students volunteered to take part in the study. They were grouped into small groups of two or three students each group; a video camera was mounted to record the discussion. No observer was present since we wanted the students to be comfortable in the discussion and in their comments and attitudes.

Our intention was to record and analyse individual student's responses, and we considered that this was most easily done by encouraging group discussions in which students were trying to interpret the concept of motion. The group discussions were open and sometimes became intense as students discussed and tried to convince each other with arguments and responded to four separate questions. The students took notes and did their calculations on paper, and each session was recorded for about $1 \mathrm{~h}$. The transcription was based on the group discussion, but the focus of the analysis was on the individually expressed interpretations of the situation. Our citations from students' reasoning where transcribed directly from the video film we analysed. When we categorized students' answers, we were not mainly interested in right or wrong answers, but more in the state of conceptual development.

As we engaged in analysis of the transcripts, we were guided by the notation that the transcription must be selective to facilitate analysis of data (Linell, 1994). However, we chose not to consider some variables, for example, body gestures and tone of voice. Transcription on the other hand has been designed as written linguistic constructions, and great importance has been given to accurate presentation of students' statements. Following Linell (1994), we decided to view the transcriptions as open units of analysis, which means that we could omit or include conventions, symbols or pauses based on the nature of the study.

Three main categories could be identified; category A (most developed responses), category $\mathrm{B}$ (less developed responses) and category $\mathrm{C}$ (least developed responses). We give examples of student's utterances with one group in each category. The students are: Student 1, Student 2, \& Student 3 (category A), Student 4, Student 5, \& Student 6 (Category B), and Student 7, \& Student 8 (Category C). 


\section{Situation and Questions}

When we face a mathematical symbolical description of an event, we need a mathematical interpretation of the symbols since mathematical symbols belong to a mathematical world. But we also try to understand the event that took place and sometimes we do this with non-mathematical references. Since we wanted the students to analyse and make interpretations of a situation in mathematical terms they were given the following situation. We knew that the students had experienced linear motion in different ways. In teaching of mathematics and physics, in textbooks and in the curriculum, is linear motion an important issue.

An object is moving according to $d(t)=2 t+t$, where $0 \leq t \leq 8$. The distance $d$ is in meters and the time $t$ is measured in seconds.

a) Calculate and interpret

$$
\frac{d(5)-d(3)}{5-3}
$$

b) How far has the subject moved after 8 seconds?

c) What velocity has the subject after 8 seconds? How do you know that?

\section{Results}

As we mentioned earlier, we have categorized student's utterances relative to the questions. The purpose was to organize the presentation of results and to facilitate analysis. Below follow student's utterances within three identified categories.

\section{Category A, Most Developed Responses}

Interpretations within this category are typically rooted in the second mathematical world, the proceptual-symbolical world, Tall (2004). The question a) is intended for illuminating student's interpretation of a difference quote for a given function. The students were asked to calculate and interpret the difference quote 
$d(5)-d(3)$

$5-3$

of the distance function $\mathrm{d}(\mathrm{t})=2 \mathrm{t}^{2}+\mathrm{t}$, where $0 \leq t \leq 10$.

Written responses (Task a))

Student 1:

$\frac{\left(2 \cdot 5^{2}+5\right)-\left(2 \cdot 3^{2}\right)}{5-3}=\frac{34}{2}=17$

Average velocity between 3 and 5 seconds is $17 \mathrm{~m} / \mathrm{s}$

Student 3:

$\frac{2 \cdot 25+5-\left(2 \cdot 3^{2}+3\right)}{2}=\frac{55-21}{2}=17$

Average velocity between 3 and 5 seconds is $17 \mathrm{~m} / \mathrm{s}$

Student 2:

$\frac{2 \cdot 25+5-2 \cdot 3^{2}+3}{2}=\frac{55-21}{2}=17$

The average velocity between 3 and 5 seconds is $17 \mathrm{~m} / \mathrm{s}$

Quotes from transcribed video material (Task a))

Student 3: Yes, but after 5 seconds has it moved some length.

Student 1: Exactly and then we must divide with... Here are my calculations...

Student 1: What we have is average velocity, right?

Student 3: 34, so I use 17 then.

Student 3: The average velocity between 3 and 5 seconds.

The subtask b) resulted in that the students in this category calculated the value of the function in the given point and they interpreted this as the distance the object has been moved after 8 seconds.

Written responses (Task b))

Student 1: Enter $t=8 \Rightarrow 2 \cdot 8^{2}+8=136$, the car has moved 136 meters

Student 2: Enter $t=8$ and it will give us $d(8)=2 \cdot 8^{2}+8=136$ meters

The car has moved $136 \mathrm{~m}$ after 8 seconds.

Quotes from transcribed video material (Task b))

Student 1: Calculate and enter...

Student 2: It should be 8, yes?

Student 3: ... 136...

Student 1: 136 meters...

Student 3: The car has moved 136 meters 
These students are following a similar reasoning in which 8 seconds is entered into the functions expression and the resulted value is interpreted as a distance. We also notice that the students associate the question as a reallife situation by labelling the moving object as a car.

The next subtask is about the object's velocity after 8 seconds. This task may be solved in different ways depending on what method the students select. The students are expected to explain why they selected a certain method.

Written responses (Task c))

Student 1: $d(t)=2 t^{2}+t$

$$
\begin{aligned}
& : d^{\prime}(t)=4 t+1 \\
& : d^{\prime}(8)=4 \cdot 8+1=33
\end{aligned}
$$

Student 1: When we find the derivative, we get the change of velocity and if we replace $t$ with 8 then we get the velocity after 8 seconds.

Student 2: $d(t)=2 t^{2}+t$

: Find the derivative $d^{\prime}(t)=4 t+1$ and set $t=8$

$: d^{\prime}(8)=4 \cdot 8+1=33 \mathrm{~m} / \mathrm{s}$

Student 2: We get the rate of change in the point when $t=8$ and in this case, it resulted in $33 \mathrm{~m} / \mathrm{s}$.

In their written answers above, the students decided to calculate and interpret the derivative of the function $\mathrm{d}(\mathrm{t})$ and thereafter they calculate the value of the function's derivative in the point 8 seconds. The students validate their method by the statement "we get the rate of change of velocity."

Quotes from transcribed video material (Task c))

Student 3: What velocity has the car after 8 seconds? How do you know that? How quick has it moved, that must be the derivative...

Student 1: Yes, for that ... that...

Student 3: Yes, because then we get that... what it is called...

Student 2: ... rate of change of velocity...

Student 3: Yes.

Student 2: So it must be 4t.

Student 3: If we use the derivative, then we get ... eh unit ... meters per second for example.

Student 2: So ... the velocity is 33 meters per second...

Student $1: 4 \mathrm{t} \ldots$ 
Student 3: Just write 4t. Add one since the $\mathrm{t}$ will become a one.

Student 2: But just write...

Student 1: $4 \times 8+1$ is equal to $33 \ldots$

Student 3: How do we know that? Because the derivative of a function is

Student 2: Well ... it says ... how do we know that really? That is what we are saying! Yes...

Student 2: Should we write it down ...

Student 1: No, we are saying it now. We are writing that the derivative ... of... a function ... is a ... certain point...

Student 3: Yes, ... point... will give us... so! Yes, we are about ready now.

\section{Category B, Less Developed Responses}

Interpretations within this category are partly rooted in the second mathematical world, the proceptual-symbolical world, Tall (2004). Similar to interpretations and utterances from students in category A, student responses in this category also demonstrate some understanding of symbols and their meaning through mathematical operations.

Written responses (Task a))

Student 5: $d(5)=2 \cdot 5^{2}+5=55$

$$
\begin{aligned}
& : d(3)=2 \cdot 3^{2}+3=21 \\
& \frac{55-21}{5-3}=\frac{34}{2}=17 \text { meters } / \mathrm{s}
\end{aligned}
$$

Student 6: $\frac{d(5)-d(3)}{5-3} \Rightarrow 17 \mathrm{~m} / \mathrm{s}$

Student 4: $d(t)=2 \cdot t^{2}+t$

Student 4: $d(5)=2 \cdot 5^{2}+5=55$

Student 4: $d(3)=2 \cdot 3^{2}+3=21$

Student $4: \frac{55-21}{5-3}=\frac{34}{2}=17 \mathrm{~m} / \mathrm{s}$

These utterances are almost identical to the utterances from the students in category A. These students interpret symbols as algebraically operations on real numbers, such as addition, division and squaring. After that they do interpretations of what the calculations means.

Quotes from transcribed video material (Task a)) 
Student 5: Within this interval it must be ... 17 meters per second.

Student 4: How do we interpret this... this ...

Student 5: I think that the interpretation is that this is the velocity ...

Student 4: Are we not supposed to say instantaneous... that is what is it... rate of change velocity ... what is it called, the average rate of change velocity ...

Written responses (Task b))

Student 5: $d(8)=2 \cdot 8^{2}+8=136$ meters

Student 6: $d(8) \Rightarrow 136$ meters

Student 4: $d(8)=2 \cdot 8^{2}+8=136$ meters

Quotes from transcribed video material (Task b))

Student 5: .. 8 seconds ... just enter 8 seconds ...

Student 6: Where the $t$ is ...

Student 4: Well $8 \cdot 8$ is $64,64 \cdot 2$ is 128 plus 8 , and equals $136 \ldots$

Student 5: $128+8 \ldots$ yes... $136 \ldots$

In task c) the students were asked to use a method for the calculation of instantaneous velocity. The students do interpretations and give utterances that mirror their concept images related to mathematical concepts.

Written responses (Task c))

Student 5: $136 / 8=17 \mathrm{~m} / \mathrm{s}$

Student 6: $s / t=136 / 8 \Rightarrow 17 \mathrm{~m} / \mathrm{s}$

Student 4: $136 / 8=17 \mathrm{~m} / \mathrm{s}$

These written utterances show how the students interpret the velocity after 8 seconds, the instantaneous velocity, to be calculated as the average velocity during the first 8 seconds. The utterance below shows Student 5's reasoning around this method.

Quotes from transcribed video material (Task c))

Student 5: What velocity has the subject after 8 seconds... it is 136 divided by $8 \ldots 136$ divided by $8 \ldots$ is this right? ... When writing what we knew we should write that we divide the distance with the time ...

\section{Category C, Least Developed Responses}

Interpretations within this category is limitedly related to the second mathematical world, the proceptual-symbolical world, Tall (2004).

Written responses (Task a)) 
Student 7: $d(5)=2 \cdot 5^{2}+5=55$

$$
\begin{aligned}
& : d(3)=2 \cdot 3^{2}+3=21 \\
& : \frac{55-21}{5-3}=\frac{34}{2}=17 \text { meters } / \mathrm{s}
\end{aligned}
$$

The distance after 5 seconds is 55 meters and the distance after 3 seconds is 21 meters. The result after subtraction and division is 17 meters.

Student 8: $d(5)=2 \cdot 5^{2}+5=55$ and $d(3)=2 \cdot 3^{2}+3=21$

Student 8: $\frac{55-21}{2}=\frac{34}{2}=17$

I calculate the distance after 5 and after 3 seconds. Then I subtract and divide and I get 17 meters.

Quotes from transcribed video material (Task a))

Student 7: I am working with the a) task, I am trying to figure it out... 5 times 5 is 25 correct... Hehe

Student 8 Oh no... We have to use some division algorithm.

Student 8 : It will be $2 \ldots$ like this ... since it will be 34 at the top and then here under ...

Student $7: 17 \ldots$

Student 8: Yes, $17 \ldots$

Student 7: I think it would be good to start with b) ... Written responses (Task b))

Student 7: $d(8)=2 \cdot 8^{2}+8=136$ meters

Student $8: d(8)=2 \cdot 8^{2}+8=136$ meters

Quotes from transcribed video material (Task b)):

Student 7: But if we enter 8 into the formula, do we add both or what?

Student 8: ... Yes... Yes, we have to add both of them. First you write down this. And then you enter the eight.

Student 7 is not quite sure about what formula he should use to enter the 8 into. The question seems to have created some uncertainty:

Student 7: $8^{2}$ is 48 yes?

Student 8: 64 .

Student 7: ... 64...

Student 8: Why do you suggest $48 \ldots$ ?

Student 7: ... Multiplication is not my strongest ability.

Student 7: $64 \cdot 2$ is ... $124 \ldots$

Student 8: ... 128...

Student 7: ... 128 yes of course... 
Student 8: Write the unit here as well.

Student 8: Write 136 here...

Student 7 seems to have difficulties with basic procedures, for example to calculate the value of the function in task b). In task c) are the students asked to decide what velocity the subject will have after 8 seconds. The task in intended to awake the student's concept images related to derivatives. But the task does not reveal what mathematical method the students should use, instead the students must present and motivate their choice of method

Written responses (Task c))

Student $7: \frac{\Delta \mathrm{d}}{\Delta t}=\frac{136}{8}=17 \mathrm{~m} / \mathrm{s}$

Student $8: \frac{\Delta \mathrm{d}}{\Delta t}=\frac{136}{8}=17$

Quotes from transcribed video material (Task c))

Student 8: So, this is the answer...the distance...there is the distance and the time is written here. This is connected, I am quite sure.

Student 7: Now we must do division. I can't do that either. Can you help me?

Student 8 : Write 136 here... and 8 here at the side and then a line... a line under the $8 \ldots$ like this...

Student 7: A line here and then the $8 \ldots$

After some few minutes' discussion, the students arrive to:

Student 8: Now you should write 17 with unit as in 17 meters per second...

\section{Discussion}

\section{Category A}

The students written utterances show how the students through a sequence of arithmetical and algebraically operations calculate the value of the difference quote. The students are interpreting the mathematical symbolism which appears in the question a). The difference quote is treated by a sequence of arithmetical operations (process) that yields an answer. Then the students make the interpretation that they are dealing with average velocity (concept), or as Student 1 express it: "average velocity over that time". 


\section{Lingefjärd \& Farahani - The Symbolic World of Mathematics}

Students utterances show example of a coherent mathematical terminology from the proceptual-symbolical world, Gray et al. (1994), when they are addressing "interval", "average velocity" or as Student 3 express that "We have the value of $d$ for $t$ equal 5 ...".

The students reasoning show how they handle the question of substituting $t$ in the function with 8. After that they perform mathematical operations of different kinds that lead to an answer. This indicates a developed concept image that enables them to interpret symbols in the expression

$$
\frac{d(5)-d(3)}{5-3}
$$

both as a process and concept (Gray et al., 1994).

Student 3's rephrasing of the task c) shows that he/she can differentiate between average velocity and instantaneous velocity. After he/she has done that, he/she suggests a possible solution to the problem, namely calculating the derivative. Student 1, Student 2, and Student 3 seem to agree about the interpretation that instantaneous velocity is linked to the derivative. Gray et al. argue that: "We characterize proceptual thinking as the ability to manipulate the symbolism flexibly as process or concept" (Gray et al., 1994, p. 7). The utterances from these students implies that the symbol $d^{\prime}(t)$ is interpreted both as a sequence of operations (process) and as rate of change of velocity (concept).

In the group with Student 1, Student 2, and Student 3 the question arouses associations to rules for derivatives. Student 1 spontaneously says " $4 t$ " before he/she mentions the concept of derivative while Student 3 express that the " $t$ becomes one". We see that concept images which connects to rules for derivation have been activated for these students before they mentioned the concept derivative. Tall et al., 1981, call this an evoked concept image.

Furthermore, the students show that they link a process (find the derivative of a function) and concept (rate of change of velocity) which according to Gray et al. (1994) is characterized as learning in the proceptual-symbolic mathematical world.

The students select the method of calculating the derivative of the function and then they calculate the derivative in that point after 8 seconds. The students express themselves about derivative as a local property, see in 
for instance Student 1's statement: "rate of change of velocity in exactly that point".

\section{Category B}

These students do not seem to have any major difficulties with calculation of the difference quote which once again show that their concept images linking together mathematical symbols and processes (Gray et al., 1994). Student 5 do the interpretation "velocity", while Student 4 go a step further and express "the average rate of change". Similar to student's interpretations in category A, these students' express utterances that indicate concept images that are linking together symbols and processes.

Nevertheless, Student 6 use the symbol for implication as an equal sign in her answer, thereby indicating the difficulty to distinguish implication from equation.

Student 5 \& Student 4 expresses opinions that do not distinguish instantaneous value and average value of velocity. It may depend on "distance over time" as a dominating component in the concept image, which is easy activated and evoked here. Hähkiöniemi (2006) argues that "distance-time functions may help them to activate their past experiences." (Hähkiöniemi, 2006, p. 75). Student 5, Student 6, and Student 4 have been introduced to derivative and its applications but the question c) do not seem to evoke concept images to relate derivative to the instantaneous velocity. The transition between average velocity and instantaneous velocity is cognitively challenging.

\section{Category C}

Both Student 7 and Student 8 found it easy to determine the value of the difference quote. They showed necessary knowledge about how to calculate the difference quote to a given function. They are also using suitable unites. But even if they can calculate the value, they are unsure about how to interpret the meaning of the value. Student 7 even suggest that they should start with b) to avoid answer the question. In Student 8's response there are indications of understanding of symbols as processes: "Just enter the eight". 


\section{Lingefjärd \& Farahani - The Symbolic World of Mathematics}

Hähkoniemi's model of Tall's (2004) and Gray's et al.'s (1994) theory of the three mathematical worlds include the concept of difference quote as a step in the learning the concept of derivatives in the proceptualsymbolical world. When Student 7 and Student 8 calculates the value of the difference quote in a) they are navigating in this world. The characterisation of learning mathematical concepts in this world is the ability to interpret mathematical symbolism both as a process and as a concept. The expression $\mathrm{d}(5)$ can both be expressed as a process (the real number 5 is entered into the expression and thereafter is the value of the difference and of the quote calculated.), and also as a concept (the distinct value of a function with respect to a given value for a variable in the definition set for the function).

Both Student 7 and Student 8 knows how the symbolical language in the expression should be interpreted, their concept images of difference quote are associated to an algorithm or to a sequence of operations. This clearly fulfils one criterion for mathematical conceptual understanding in the proceptual-conceptual world. Both Student 7 and Student 8 seem to lack the part of concept images which could enable them to link symbols and concepts, such as symbols in the difference quote and average value of velocity.

Student 7 makes the interpretation that the distance function is a "formula" that he can use to enter a value to calculate a new value. This interpretation reflects Student 7's concept image of a function. Vinner \& Dreyfus (1989) showed that students sometimes perceive a function as an operation which calculates a new number from an input number or as a formula in an algebraically expression.

The historical and psychological aspects make it hard to introduce function related concepts in such a way that students enable a developed understanding and thereby can transform the concept into other situations. Sometimes concepts within mathematics are comprehended as symbolic and not visual.

Student 7 and Student 8 do not differentiate average velocity and instantaneous velocity in a specific way which possibly indicates that the students are unable to interpret the expression

$\frac{d(5)-d(3)}{5-3}$

as average velocity during the time from three to five seconds. 


\section{Conclusions}

On a general level, we believe that when analysing student's utterances in this specific way, we also found a lot about how to teach future students. One specific finding is that almost every group associated the object that was moving into the concept of a car. It seemed as if the students became more comfortable when thinking, and talking, about a moving car. On the other hand, cars are probably seldom driven in a route that can be modelled by a parabola. None of the students associated the symbolic representation into a graphical representation (i. e. sketched a graph of the "car's displacement), even though this should have been quite easy for them from a pure mathematical standpoint. From a cognitive standpoint, it is perhaps challenging to do that transition. The students probably did not consider the graphical representation as the easiest way, or perhaps they did not even consider a graphical representation at all. On the other hand, these students are so called specialist in the natural science program and they have years of graphing and sketching behind them also in other subjects, such as for instance physics.

If we look at Hähkiöniemi's (2006) model in Figure 1, we see that the task could have directed the students towards the right part of the model (Symbolic) while the graphical representation probably is evoked by the left part (Embodied). The way we presented the situation for the students, that way we perhaps guided them away from a graphical representation that could have been of some value for them. These issues are important to have knowledge about and to address in the teaching and learning process.

Students often seem to be able to calculate and to receive the correct answer, yet some of the students in some cases do not know exactly what the results are about. To make correct interpretations of mathematical symbols as concepts seems to be a larger challenge for the students than to interpret symbols as processes. The "rate of change" was the most dominant interpretation of the derivative in this study. Another finding was that the most developed responses used quantities as time, displacement, while the least developed responses used units such as meters and seconds.

Learning of mathematical concepts is linked together with the development of concept images. Relations between symbols and concepts need to be strengthened and conceptual development could be in focus for 
teaching of mathematics. Learning is not a matter of replacing bad minigeneralizations with good ones. Instead, it is partly a matter of tweaking those mini-generalizations into a more articulate, unified, coherent structure.

\section{References}

Breidenbach, D., Hawks, J., Nichols, D., \& Dubinsky, E. (1992).

Development of the process conception of function. Educational

Studies in Mathematics, 23(4), 247-285. doi: 10.1007/BF02309532

Elby, A. (2000). What students' learning of representations tells us about constructivism. Journal of Mathematical Behavior, 19(4), 481-502. doi: https://doi.org/10.1016/S0732-3123(01)00054-2

Friel, S. N., Curcio, F. R., \& Bright, G. W. (2001). Making sense of graphs: critical factors influencing comprehension and instructional implications. Journal for Research in Mathematics Education, 32(2), 124- 158. doi: 10.2307/749671

Gray, E. \& Tall, D. (1994). Duality, ambiguity, and flexibility: A proceptual view of simple arithmetic. Journal for Research in Mathematics Education, 25(2), 116 - 140. doi: 10.2307/749505 Hähkiöniemi, M. (2006): The Role of Representations in Learning The Derivative. PhD dissertation. University of Jyväskylä. Department of Mathematics and Statistics.

Leinhardt, G., Zaslavsky, O., \& Stein, M. M. (1990). Functions, graphs, and graphing: Tasks, Learning and Teaching. Review of Educational Research, 60(1), 1-64. doi:

https://doi.org/10.3102/00346543060001001

Linell, P. (1994). Transcription of talk and conversation. Theory and practise. Reports from Theme K: 99-0831950-7 1994: 9. Linkoping University: Sweden.

Lingefjärd, T. \& Farahani, D. (2017). The Elusive Slope. International Journal of Science and Mathematics Education. First online. doi: http://dx.doi.org/10.1007/s10763-017-9811-9

Sfard, A. (1992). Operational origins of mathematical objects and the quandary of reification - the case of function. In E. Dubinsky \& G. Harel (Eds.), The Concept of Function: Aspects of Epistemology and Pedagogy (pp. 59-84). Washington DC: MAA. 
Tall, D., \& Vinner, S. (1981). Concept image and concept definition in mathematics with particular reference to limits and continuity. Educational Studies in Mathematics, 12(2), 151-169. doi: 10.1007/BF00305619

Tall, D. (2004). Thinking Through Three Worlds of Mathematics. Proceedings of the 28th Conference of PME (pp. 281-288). Bergen, Norway.

Trigueros, M., \& Martínez-Planell, R. (2010). Geometrical representations in the learning of two-variable functions. Educational Studies in Mathematics, 73(1), 3-19. doi: 10.1007/s10649-009-9201-5

Vinner, S., \& Dreyfus, T. (1989). Images and definitions for the concept of function. Journal for research in mathematics education, 20(4), 356366. doi: $10.2307 / 749441$

Thomas Lingefjärd is senior lecturer at the University of Gothenburg, Sweden.

Djamshid Farahani is lecturer at the University of Gothenburg, Sweden.

Contact Address: Direct correspondence concerning this article, should be addressed to the author. Postal address: Department of Pedagogical, curriculum and professional studies, Box 300, 40530 Göteborg, Sweden. Email: thomas.lingefjard@gu.se 